\title{
Neuroprotective effects of Lycium barbarum polysaccharides in lipopolysaccharide-induced BV2 microglial cells
}

\author{
PENG TENG $^{1 *}$, YUNHONG LI $^{1 *}$, WENJING CHENG ${ }^{1}$, LIANG ZHOU ${ }^{2}$, YING SHEN $^{2}$ and YIN WANG ${ }^{1}$ \\ ${ }^{1}$ Department of Neurobiology, Basic Medical College, Center of Scientific Technology, \\ Cranial Cerebral Disease Laboratory, Ningxia Medical University, Yinchuan, Ningxia 750004; ${ }^{2}$ Department of Neurobiology, \\ Key Laboratory of Medical Neurobiology of the Ministry of Health, Zhejiang Province Key Laboratory of Neurobiology, \\ Zhejiang University School of Medicine, Hangzhou, Zhejiang 310058, P.R. China
}

Received November 9, 2012; Accepted April 22, 2013

DOI: $10.3892 / \mathrm{mmr} .2013 .1442$

\begin{abstract}
Polysaccharides extracted from Lycium barbarum (LBPs) possess a wide variety of biological activities. However, their neuroprotective effects have not yet been fully elucidated. The aim of the present study was to investigate the inhibitory effects of LBPs on the production of lipopolysaccharide (LPS)-induced proinflammatory mediators in BV2 microglia. BV2 mouse microglial cells were cultured and an MTT assay was performed to determine whether LBPs had an effect on the apoptosis of LPS-stimulated BV2 cells. Our data showed that LPS induced the activation of nuclear factor $-\kappa \mathrm{B}(\mathrm{NF}-\kappa \mathrm{B})$ and its upstream protein caspase 3, upregulated the expression of an additional apoptosis-inducing factor, heat shock protein 60 (HSP60), in BV2 microglial cells and increased the release of TNF- $\alpha$ and HSP60 in the culture media. Following treatment with LBPs, the activated NF- $\kappa \mathrm{B}$ and caspase 3 were significantly suppressed. Furthermore, the enhanced expression of HSP60 was reduced and the LPS-induced release of TNF- $\alpha$ and HSP60 were inhibited. These results suggest that LBPs may have therapeutic potential for the treatment of neurodegenerative diseases that are accompanied by microglial activation.
\end{abstract}

\section{Introduction}

Microglial cells, the resident brain macrophages of the central nervous system (CNS), play a prominent role in the pathogenesis of neurodegenerative disorders (1). In response to environmental stress or lipopolysaccharide (LPS) exposure,

Correspondence to: Professor Yin Wang, Department of Neurobiology, Basic Medical College, Center of Scientific Technology, Cranial Cerebral Disease Laboratory, Ningxia Medical University, 1160 Shengli Street, Yinchuan, Ningxia 750004, P.R. China

E-mail: yin-wang@hotmail.com

${ }^{*}$ Contributed equally

Key words: polysaccharide, BV2 microglia, nuclear factor- $\kappa \mathrm{B}$, caspase 3, heat shock protein 60 microglia are activated and become involved in the innate and adaptive immune responses via the production of proinflammatory mediators, including nuclear factor- $\kappa \mathrm{B}(\mathrm{NF}-\kappa \mathrm{B})$, caspase 3 and heat shock protein 60 (HSP60) (2-6). It has been demonstrated that extracellular HSP60 increases the production of proinflammatory factors in microglia, which causes neuronal damage $(7,8)$. Therefore, the control of HSP60 production may be an effective therapeutic option for the treatment of neurodegenerative diseases. Currently, a limited number of disease-modifying treatment approaches are used or are under investigation as therapeutic interventions in CNS injuries and neurodegenerative diseases $(9,10)$. For example, it has been shown that minocycline possesses anti-apoptotic and anti-inflammatory actions in animal models of CNS injuries and neurodegenerative diseases $(11,12)$. However, the complexity of current pharmacological agents has delayed their development for the treatment or prevention of CNS diseases.

Lycium barbarum, a traditional Chinese medicine, has been used as a food supplement for centuries. Previous studies have shown that Lycium barbarum possesses eye-protective (13), anti-aging (14), immunoregulating (15) and antitumor properties $(15,16)$. Polysaccharides are the major active ingredient in Lycium barbarum (LBPs). Although the benefits of Lycium barbarum and LBPs have been recognised, their functions in the CNS are poorly understood. A limited number of studies have shown that LBPs prevent $\beta$-amyloid peptideor glutamate-induced neurotoxicity in cultured cortical neurons $(17,18)$. The effects of LBPs on neuroimmune diseases have not yet been fully elucidated.

In the present study, we aimed to investigate the effects of LBPs on LPS-induced inflammatory injury in BV2 microglia cells. Our results showed that LBPs suppress the increased levels of caspase 3, TNF- $\alpha$ and HSP60 caused by LPS treatment, possibly via NF- $\kappa \mathrm{B}$ inhibition. Therefore, the extract from Lycium barbarum may be used to control the activation of microglia and their induction of the inflammatory response in the CNS.

\section{Materials and methods}

Chemicals. LBPs (purity $>95 \%$, data not shown) were purchased from Ningxia Qiyuan Pharmaceutical Company 
(Yinchuan, China). Antibodies against GAPDH, lamin B and NF- $\mathrm{KB}$ were from Abcam (Cambridge, MA, USA). The anti-HSP60 antibody was from Stressgen (San Diego, CA, USA) and the anti-caspase 3 antibody was from Cell Signaling Technology, Inc. (Beverly, MA, USA). The proteinase inhibitor cocktails were from Merck Chemicals (Whitehouse Station, NJ, USA). HSP60 and TNF- $\alpha$ enzyme-linked immunosorbent assay (ELISA) kits were from Yaji (Shanghai, China) and eBioscience (San Diego, CA, USA), respectively. BCA and ECL kits were from Pierce (Rockford, IL, USA). Dulbecco's modified Eagle's medium (DMEM) and fetal bovine serum (FBS) were from Gibco (Grand Island, NY, USA). All the additional chemicals were purchased from Sigma (St. Louis, MO, USA), unless otherwise stated.

Microglia cell culture. BV2 mouse microglial cells were cultured in DMEM supplemented with 10\% FBS, penicillin $(100 \mathrm{U} / \mathrm{ml})$ and streptomycin $(100 \mathrm{~g} / \mathrm{ml})$. Cultures were maintained at $37^{\circ} \mathrm{C}$ in a humidified incubator gassed with $95 \%$ $\mathrm{O}_{2}$ and $5 \% \mathrm{CO}_{2}$. LBPs were dissolved in phosphate-buffered saline (PBS). The final concentration of PBS in the medium was $<0.05 \%$ (vol $/ \mathrm{vol})$ and this demonstrated no effect on cell growth (data not shown). The cells were treated with the indicated concentrations of LBPs for $24 \mathrm{~h}$ following the administration of LPS (200 ng/ml).

Cell viability assay. Cells ( $3 \times 10^{4}$ cells in $200 \mu \mathrm{l} /$ well) were seeded in 96-well plates. An MTT assay was used to assess the percentage of viable cells following pharmacological treatments, as previously described (19). Briefly, the culture medium in the 96-well plates was replaced by $100 \mu \mathrm{l}$ of fresh MTT solution $(0.5 \mathrm{mg} / \mathrm{ml})$ following the treatments. After $3 \mathrm{~h}$ of incubation at $37^{\circ} \mathrm{C}$, the supernatant was removed and formazan salt crystals dissolved in $150 \mu \mathrm{l}$ dimethyl sulfoxide (DMSO) were added to the cells. Cell viability was measured by the absorbance at $570 \mathrm{~nm}$. The cell survival ratio was calculated by normalization to the control.

ELISA. The levels of HSP60 and TNF- $\alpha$ in the culture medium were quantified according to the manufacturer's instructions. Absorbance was determined at $450 \mathrm{~nm}$ using a microplate reader.

Western blot analysis. The cells were washed with PBS three times and lysed with RIPA buffer. The protein concentration was determined using a BCA kit, according to the manufacturer's instructions. Equal quantities of protein were loaded and run on SDS/polyacrylamide gels and then transferred to PVDF membranes. The membranes were blocked with 5\% dried milk and incubated with the primary antibodies in TBST overnight at $4^{\circ} \mathrm{C}$. After being rinsed in milk-TBST, blots were incubated in the horseradish peroxidase-conjugated secondary antibodies. The target proteins were detected using the enhanced chemiluminescence (ECL) detection system and X-ray films.

Statistical analysis. Statistical differences were determined using a one-way ANOVA test. $\mathrm{P}<0.05$ was considered to indicate a statistically significant difference. Data in the text and figures are presented as the mean \pm standard error of the mean $(\mathrm{SEM}) . \mathrm{n}$ represents the number of experiments.

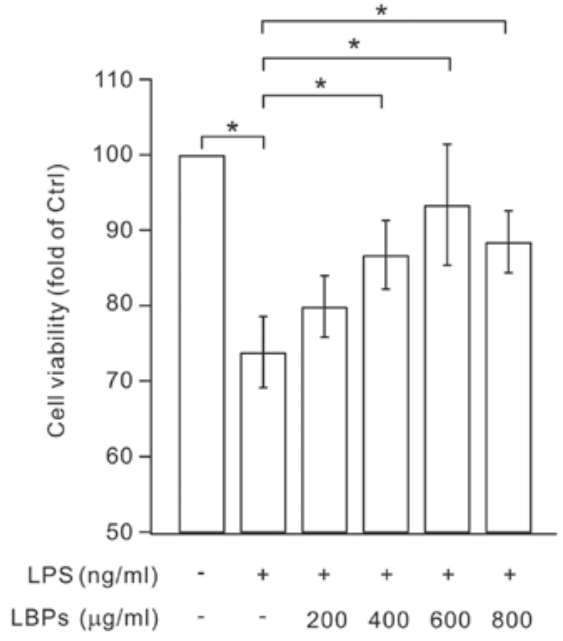

Figure 1. Lycium barbarum polysaccharides (LBPs) increased the cell viability of BV2 microglia. BV2 cells were treated with lipopolysaccharide (LPS; $200 \mathrm{ng} / \mathrm{ml}$ ) for $1 \mathrm{~h}$, followed by treatment with various concentrations of LBPs $(0,200,400,600$ or $800 \mu \mathrm{g} / \mathrm{ml})$ for $24 \mathrm{~h}$. The viability of untreated cells was set to 100 . The viability of LPS and LBP-treated cells was expressed as the percentage of the untreated cells (controls, Ctrl). Results were obtained from three independent experiments. ${ }^{*} \mathrm{P}<0.05$.

\section{Results}

LBPs promote the viability of BV2 microglia. An MTT assay was performed to determine whether LBPs had an effect on the apoptosis of LPS-stimulated BV2 cells. The results demonstrated that the treatment of microglia with $1,000 \mu \mathrm{g} / \mathrm{ml}$ LBPs for up to $24 \mathrm{~h}$ did not increase the viability of LPS-stimulated BV2 cells (data not shown). However, lower concentrations of LBPs (200-800 $\mu \mathrm{g} / \mathrm{ml})$ significantly increased cell viability compared with the LPS group (Fig. 1). These results indicate that LBPs have a positive effect on the viability of LPS-stimulated BV2 microglia.

Effects of LBPs on NF- $\kappa B$, caspase 3 and HSP60 protein expression in LPS-stimulated BV2 microglia. NF- $\mathrm{\kappa B}$ regulates the expression of numerous proinflammatory factors (20). Therefore, we examined the NF- $\mathrm{kB}$ level following LBPs treatment. Fig. 2A shows that levels of the p65 subunit of $N F-\kappa B$ increased with LPS treatment, but was markedly inhibited by LBPs. Caspase 3 is the upstream protein of the $\mathrm{NF}-\mathrm{\kappa B}$ signaling pathway. Inhibition of caspase 3 prevents neuronal loss in brain diseases, including activated microglia. Thus, we examined the effects of LBPs on caspase 3 expression (Fig. 2B). Our results showed that caspase 3 expression was suppressed following LBPs treatment. NF- $\mathrm{kB}$ has been shown to initiate the transcription of the HSP60 stress protein gene, which elicits a potent proinflammatory response in innate immune cells. Results from a previous study have demonstrated that LPS increases HSP60 expression in BV2 microglial cells (6). The results of the present study also showed that HSP60 expression markedly increased following LPS treatment. However, LBPs treatment significantly inhibited this HSP60 enhancement (Fig. 2C). These results suggest that the anti-inflammatory effects of LBPs may be associated with the inhibition of NF- $\mathrm{kB}$ signaling. 
A
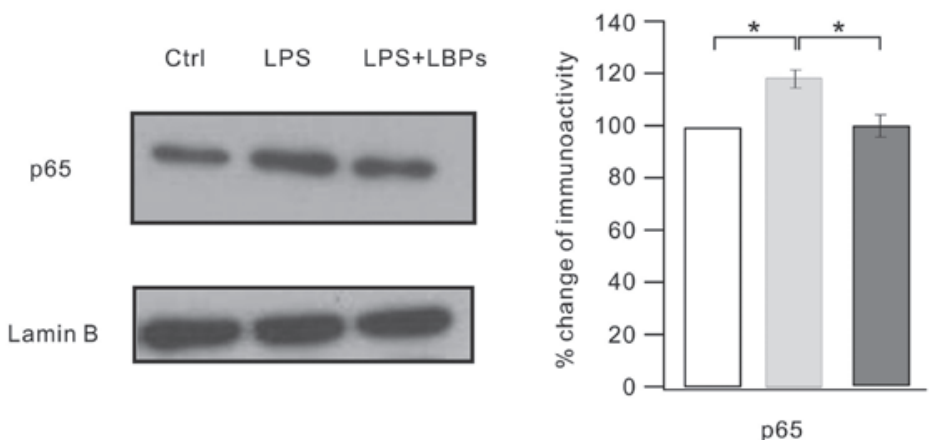

B
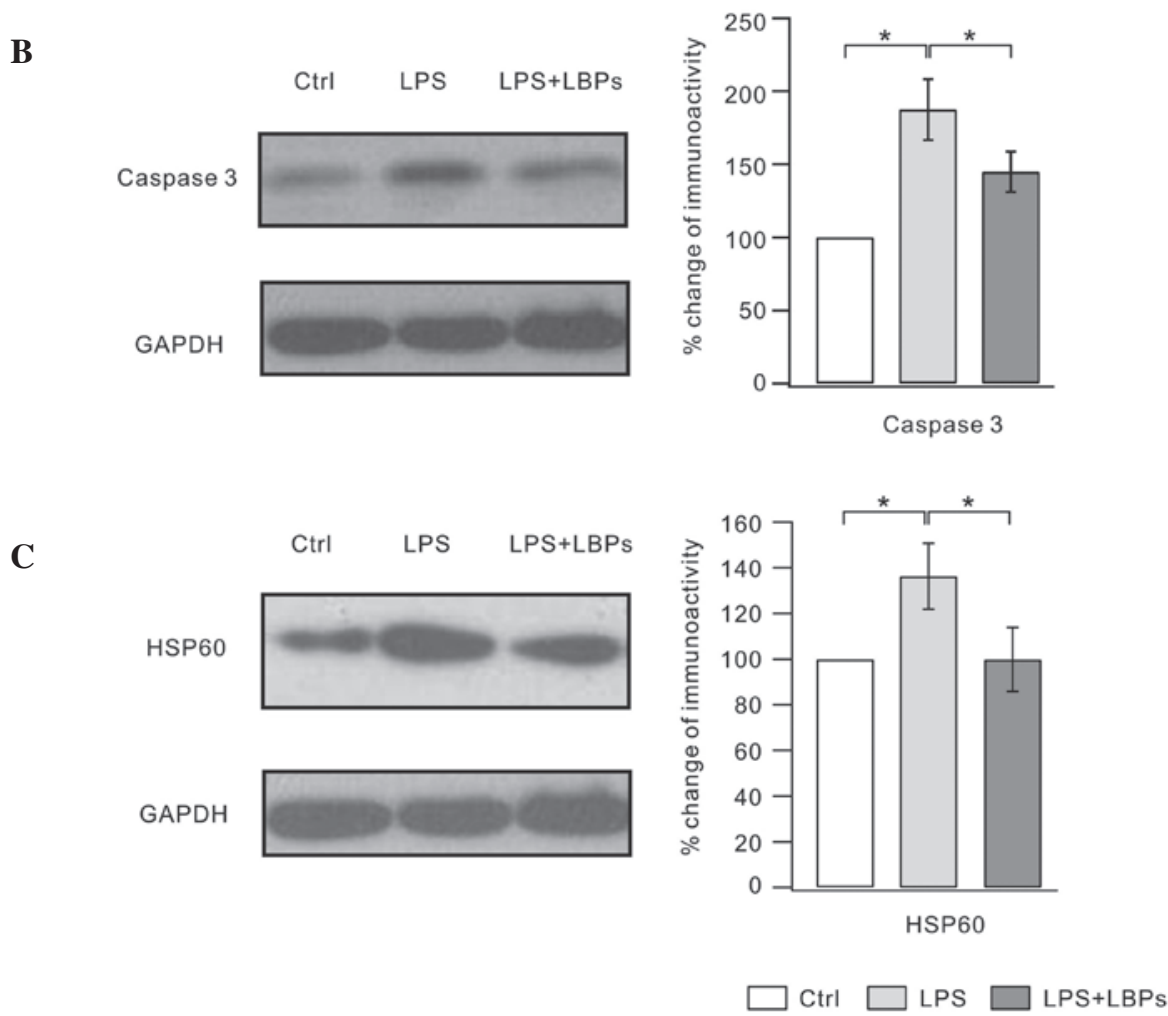

Figure 2. Lycium barbarum polysaccharides (LBPs) inhibited the increased expression of NF- $\kappa$ B, caspase 3 and HSP60 in lipopolysaccharide (LPS)-stimulated BV2 microglia. Cells were pretreated with LPS for $1 \mathrm{~h}$, followed by an incubation with $600 \mu \mathrm{g} / \mathrm{ml}$ LBPs for $24 \mathrm{~h}$. (A) The lysates were probed by immunoblotting with antibodies against $\mathrm{p} 65$ and lamin B. The right panel shows ratios of the signal intensity of p65/lamin B (Ctrl, 100\%; LPS, $119.3 \pm 7 \%$; LPS + LBP, $107.3 \pm 9 \%$ ). (B) The lysates were probed by immunoblotting with antibodies against caspase 3 and GAPDH. The right panel shows ratios of the signal intensity

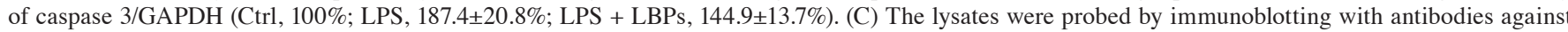

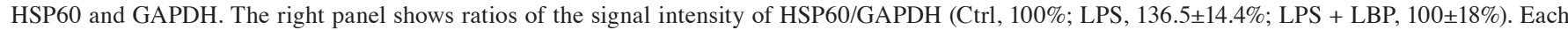
experiment was derived from 10 independent cultures. ${ }^{*} \mathrm{P}<0.05$. Ctrl, control.

A

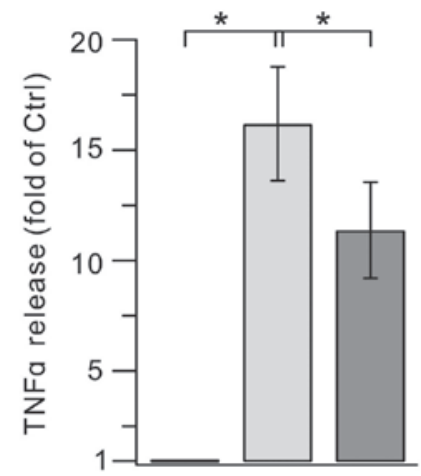

B

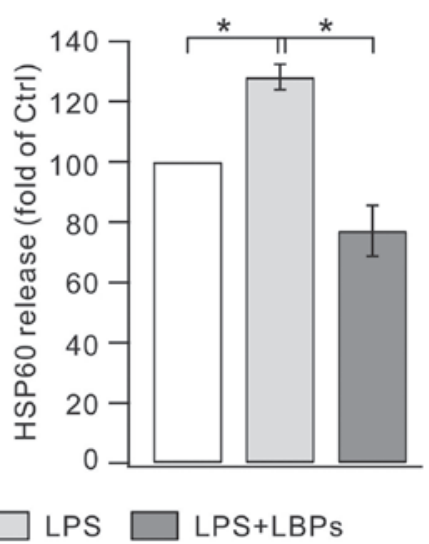

Figure 3. Lycium barbarum polysaccharides (LBPs) decreased the production of TNF- $\alpha$ and HSP60 in lipopolysaccharide (LPS)-stimulated BV2 microglia. Cells were pretreated with LPS for $1 \mathrm{~h}$, followed by an incubation with $600 \mu \mathrm{g} / \mathrm{ml} \mathrm{LBPs}$ for $24 \mathrm{~h}$. Extracellular levels of (A) TNF- $\alpha$ and (B) HSP60 were measured using an ELISA assay. Results are representative of three independent experiments. ${ }^{*} \mathrm{P}<0.05$. Ctrl, control. 
Effects of LBPs on the expression of TNF- $\alpha$ and HSP60 by LPS-stimulated BV2 microglia. An ELISA assay was used to investigate whether LBPs suppressed the release of TNF- $\alpha$ from LPS-stimulated BV2 cells. As shown in Fig. 3A, the 24-h LPS treatment of BV2 cells resulted in a marked increase in TNF- $\alpha$ levels compared with the controls. The application of LBPs significantly decreased the concentration of TNF- $\alpha$ in the culture media. Previous studies suggest that upon stress, HSP60 is upregulated and released into the extracellular space, where it exerts injury effects $(21,22)$. We hypothesized that LPS also induces the increase of HSP60 in the extracellular space and this was confirmed by our experiment (Fig. 3B). LPS alone $(200 \mathrm{ng} / \mathrm{ml})$ markedly increased the HSP60 release compared with the controls. LBPs significantly reduced the HSP60 concentration in the medium. These results indicate that LBPs effectively suppress the production of TNF- $\alpha$ and HSP60 by over-activated microglia.

\section{Discussion}

Over-activated microglia produce cytokines and cause neuronal inflammatory responses following LPS exposure (5). In the present study, we showed that treatment with $600 \mu \mathrm{g} / \mathrm{ml}$ LBPs effectively suppressed the activation of microglia. LPS treatment increased the expression of caspase 3 and HSP60, whereas LBPs treatment markedly suppressed their expression. Treatment with LBPs also effectively prevented the release of TNF- $\alpha$ and HSP60 into the culture medium. The effects of LBPs may occur via NF- $\kappa$ B inhibition, since p65 expression was decreased with LBPs treatment. Therefore, our data suggest that LBPs may be a therapeutic agent for the treatment of inflammatory diseases.

Microglia defend the brain by destroying invading pathogens in the innate immune response of the CNS (23). Moderate microglia activation promotes neuronal survival in ischemia (24). However, the over-activation of microglia leads to the harmful activation of NF- $\mathrm{kB}$ signaling and TNF- $\alpha$ release in inflammatory responses and organ failure (25). Therefore, the inhibition of proinflammatory enzymes and cytokines may be an effective therapeutic approach against neurodegenerative disorders and it is of therapeutic importance to seek new strategies to decrease the over-activation of microglia. Previous studies have investigated the neuroprotective effects of several natural extracts, including curcumin (26) and fucoidan (27). The present study suggests that the extract from Lycium barbarum is a potential therapeutic tool.

Caspases are essential for apoptosis and inflammation and caspase 3 is crucial in cell death and CNS inflammation (28). It has been reported that LPS-stimulated microglia are not toxic to neighboring neurons when caspase $3 / 7$ is inhibited (29). The activation of NF- $\mathrm{KB}$ by caspase 3 is critical in inflammation. $\mathrm{NF}-\kappa \mathrm{B}$ is the most important transcription factor for inducing the transcription of proinflammatory genes. For example, the activation of NF- $\mathrm{KB}$ leads to ischemia-induced neuronal injury (30). Therefore, several anti-inflammatory therapies aim to inhibit NF- $\kappa \mathrm{B}$ activity in LPS models or inflammatory diseases (31). Our results demonstrate that LBPs treatment markedly inhibits caspase 3 and the NF- $\mathrm{KB}$ downstream mediator p65, suggesting that the anti-inflammatory effects of LBPs may be a result of the inhibition of the NF- $\kappa B$ pathway.
HSP60 is a member of the heat shock protein family. HSP60 is normally cytoprotective, however, it may become toxic by targeting self-reactive $\mathrm{T}$ cells in inflammatory diseases (32). HSP60 production is induced by the NF- $\mathrm{KB}-\mathrm{p} 65$ cascade and is released following oxidative stress (33). The regulation of HSP60 gene expression via the binding of NF- $\mathrm{KB}$ to the HSP60 gene promoter may be the mechanism via which these effects occur (34). TNF- $\alpha$ is also a mediator of NF- $\mathrm{KB}$ signaling and triggers an increase in the expression of HSP60, which has been shown to be reversed by p65 inhibition (34). We showed that the levels of HSP60, NF- $\mathrm{KB}$ and TNF- $\alpha$ are decreased by LBPs. Combined with the data of our previous studies, our results indicate that LBPs may act through the inhibition of $\mathrm{NF}-\kappa \mathrm{B}$ to prevent the over-activation of microglia.

\section{Acknowledgements}

This study was supported by grants from the National Natural Science Foundation of China (30960108, 31060140, 31070945, 31100780, 81060034 and 31260243) and LY12C09002. This study was also supported by SRF for ROCS, State Education Ministry (SEM) and Program for New Century Excellent Talents in University 'NCET' for Dr Yin Wang.

\section{References}

1. Block ML, Zecca L and Hong JS: Microglia-mediated neurotoxicity: uncovering the molecular mechanisms. Nature Rev Neurosci 8: 57-69, 2007.

2. Hanisch UK and Kettenmann H: Microglia: active sensor and versatile effector cells in the normal and pathologic brain. Nat Neurosci 10: 1387-1394, 2007.

3. Gehrmann J, Matsumoto Y and Kreutzberg GW: Microglia: intrinsic immuneffector cell of the brain. Brain Res Brain Res Rev 20: 269-287, 1995.

4. Innamorato NG, Lastres-Becker I and Cuadrado A: Role of microglial redox balance in modulation of neuroinflammation. Curr Opin Neurol 22: 308-314, 2009.

5. Lynch MA: The multifaceted profile of activated microglia. Mol Neurobiol 40: 139-156, 2009.

6. Li YH, Teng P, Wang Y, Zhang YM, Ma CJ and Pu J: Expression and regulation of HSP60 in activated microglia cells. J Ningxia Med Univ 8: 712-714, 2011.

7. Zhang D, Sun L, Zhu H, Wang L, Wu W, Xie J and Gu J: Microglial LOX-1 reacts with extracellular HSP60 to bridge neuroinflammation and neurotoxicity. Neurochem Int 61: 1021-1035, 2012.

8. Lehnardt S, Schott E, Trimbuch T, Laubisch D, Krueger C, Wulczyn G, Nitsch R and Weber JR: A vicious cycle involving release of heat shock protein 60 from injured cells and activation of toll-like receptor 4 mediates neurodegeneration in the CNS. J Neurosci 28: 2320-2331, 2008.

9. Xia W, Han J, Huang G and Ying W: Inflammation in ischaemic brain injury: current advances and future perspectives. Clin Exp Pharmacol Physiol 37: 253-258, 2010.

10. Perry VH, Nicoll JA and Holmes C: Microglia in neurodegenerative disease. Nat Rev Neurol 6: 193-201, 2010.

11. Stirling DP, Khodarahmi K, Liu J, McPhail LT, McBride CB, Steeves JD, Ramer MS and Tetzlaff W: Minocycline treatment reduces delayed oligodendrocyte death, attenuates axonal dieback, and improves functional outcome after spinal cord injury. J Neurosci 24: 2182-2190, 2004.

12. Choi SH, Lee DY, Chung ES, Hong YB, Kim SU and Jin BK: Inhibition of thrombin-induced microglial activation and $\mathrm{NADPH}$ oxidase by minocycline protects dopaminergic neurons in the substantia nigra in vivo. J Neurochem 95: 1755-1765, 2005.

13. Li SY, Yang D, Yeung CM, Yu WY, Chang RC, So KF, Wong D and Lo AC: Lycium barbarum polysaccharides reduce neuronal damage, blood-retinal barrier disruption and oxidative stress in retinal ischemia/reperfusion injury. PLoS One 6: e16380, 2011. 
14. Li XM, Ma YL and Liu XJ: Effect of the Lycium barbarum polysaccharides on age-related oxidative stress in aged mice. J Ethnopharmacol 111: 504-511, 2007.

15. Tang WM, Chan E, Kwok CY, Lee YK, Wu JH, Wan CW, Chan RY, Yu PH and Chan SW: A review of the anticancer and immunomodulatory effects of Lycium barbarum fruit. Inflammopharmacology 20: 307-314, 2012.

16. Gong H, Shen P, Jin L, Xing C and Tang F: Therapeutic effects of Lycium barbarum polysaccharide (LBP) on irradiation or chemotherapy-induced myelosuppressive mice. Cancer Biother Radiopharm 20: 155-162, 2005.

17. Ho YS, Yu MS, Lai CS, et al: Characterizing the neuroprotective effects of alkaline extract of Lycium barbarum on beta-amyloid peptide neurotoxicity. Brain Res 1158: 123-134, 2007.

18. Ho YS, Yu MS, Yik SY, So KF, Yuen WH and Chang RC: Polysaccharides from wolfberry antagonizes glutamate excitotoxicity in rat cortical neurons. Cell Mol Neurobiol 29: 1233-1244, 2009.

19. Zhu J, Shao CY, Yang W, Zhang XM, Wu ZY, Zhou L, Wang XX, Li YH, Xia J, Luo JH and Shen Y: Chronic zinc exposure decreases the surface expression of NR2A-containing NMDA receptors in cultured hippocampal neurons. PloS One 7: e46012, 2012.

20. Sarkar FH, Li Y, Wang Z and Kong D: NF-kappaB signaling pathway and its therapeutic implications in human diseases. Int Rev Immunol 27: 293-319, 2008.

21. Hayoun D, Kapp T, Edri-Brami M, Ventura T, Cohen M, Avidan A and Lichtenstein RG: HSP60 is transported through the secretory pathway of 3-MCA-induced fibrosarcoma tumour cells and undergoes N-glycosylation. FEBS J 279: 2083-2095, 2012.

22. Rizzo M, Macario AJ, de Macario EC, Gouni-Berthold I, Berthold HK, Rini GB, Zummo G and Cappello F: Heat shock protein-60 and risk for cardiovascular disease. Curr Pharm Des 17: 3662-3668, 2011

23. Kreutzberg GW: Microglia: a sensor for pathological events in the CNS. Trends Neurosci 19: 312-318, 1996.

24. Lai AY and Todd KG: Microglia in cerebral ischemia: molecular actions and interactions. Can J Physiol Pharmacol 84: 49-59, 2006.
25. Chen J, Zhou Y, Mueller-Steiner S, Chen LF, Kwon H, Yi S, Mucke L and Gan L: SIRT1 protects against microglia-dependent amyloid-beta toxicity through inhibiting NF-kappaB signaling. J Biol Chem 280: 40364-40374, 2005.

26. Karlstetter M, Lippe E, Walczak Y, Moehle C, Aslanidis A, Mirza M and Langmann T: Curcumin is a potent modulator of microglial gene expression and migration. J Neuroinflammation 8: 125, 2011.

27. Park HY, Han MH, Park C, Jin CY, Kim GY, Choi IW, Kim ND, Nam TJ, Kwon TK and Choi YH: Anti-inflammatory effects of fucoidan through inhibition of NF- $\mathrm{BB}, \mathrm{MAPK}$ and Akt activation in lipopolysaccharide-induced BV2 microglia cells. Food Chem Toxicol 49: 1745-1752, 2011.

28. Soria JA, Arroyo DS, Gaviglio EA, Rodriguez-Galan MC, Wang JM and Iribarren P: Interleukin 4 induces the apoptosis of mouse microglial cells by a caspase-dependent mechanism. Neurobiol Dis 43: 616-624, 2011.

29. Burguillos MA, Deierborg T, Kavanagh E, Persson A, Hajji N, Garcia-Quintanilla A, Cano J, Brundin P, Englund E, Venero JL and Joseph B: Caspase signalling controls microglia activation and neurotoxicity. Nature 472: 319-324, 2011.

30. Gu JH, Ge JB, Li M, Wu F, Zhang W and Qin ZH: Inhibition of $N F-\kappa B$ activation is associated with anti-inflammatory and anti-apoptotic effects of Ginkgolide B in a mouse model of cerebral ischemia/reperfusion injury. Eur J Pharm Sci 47: 652-660, 2012.

31. Woods DC, White YA, Dau C and Johnson AL: TLR4 activates $\mathrm{NF}-\kappa \mathrm{B}$ in human ovarian granulosa tumor cells. Biochem Biophys Res Commun 409: 675-680, 2011.

32. Kapitein B, Aalberse JA, Klein MR, de Jager W, Hoekstra MO, Knol EF and Prakken BJ: Recognition of self-heat shock protein 60 by $\mathrm{T}$ cells from patients with atopic dermatitis. Cell Stress Chaperones 18: 87-95, 2013.

33. Lin L, Kim SC, Wang Y, Gupta S, Davis B, Simon SI, et al: HSP60 in heart failure: abnormal distribution and role in cardiac myocyte apoptosis. Am J Physiol Heart Circ Physiol 293: H2238-H2247, 2007.

34. Wang Y, Chen L, Hagiwara N and Knowlton AA: Regulation of heat shock protein 60 and 72 expression in the failing heart. J Mol Cell Cardiol 48: 360-366, 2010. 